\title{
RMetS
}

Royal Meteorological Society

\section{Boundary-layer simulations for the Mars Phoenix lander site}

\author{
Hannu Savijärvi ${ }^{\mathrm{a}}{ }^{\star}$ and Anni Määttänen ${ }^{\mathrm{b}}$ \\ ${ }^{a}$ Department of Physics, University of Helsinki, Finland \\ ${ }^{\mathrm{b}}$ Laboratoire Atmosphères, Milieux, Observations Spatiales, CNRS, Université Versailles St Quentin, Verrières-le-Buisson, \\ France \\ ${ }^{\star}$ Correspondence to: Hannu Savijärvi, University of Helsinki, Department of Physics, Helsinki, Finland. \\ E-mail: hannu.savijarvi@helsinki.fi
}

\begin{abstract}
Diurnal simulations and sensitivity studies were made with a moist column model at the Mars Phoenix lander site $\left(68^{\circ} \mathrm{N}\right)$ for the summer solstice (solar day 30$)$ and for a later date (sol 99), when the LIDAR on board Phoenix detected fog, dust, ice clouds and even snowfall from cloud. The sol 30 simulation reproduces the observed repetitive diurnal $2 \mathrm{~m}$ temperature cycle quite well, displaying a well-mixed boundary layer up to $4 \mathrm{~km}$ in the afternoon and a strong surface inversion to $500 \mathrm{~m}$ each night. Weak frost formation peaks at midnight and a very thin radiation fog appears during the coldest hour. The near-surface water vapour pressure is underestimated during daytime but is close to the thermal and electrical conductivity probe observations during the night. The Prandtl slope wind mechanism produces veering winds in the model as observed by the 'telltale' device while coupled dust evolution implies well-mixed dust to $4 \mathrm{~km}$ throughout the sol as observed by the LIDAR.

The colder diurnal conditions around sol 99 are also simulated rather well. In these, the morning fog grows up to $800 \mathrm{~m}$ height and a water ice cloud forms at $4 \mathrm{~km}$ height at about 0300 local time, as observed. The cloud marks the radiatively cooled top of the moist residual boundary layer. Strong ground frost formation peaks in the evening, having a visible impact on the temperatures. The fog and cloud display weak feedbacks to the modelled radiative fluxes. Copyright (c) 2010 Royal Meteorological Society
\end{abstract}

\begin{abstract}
Key Words: Martian atmosphere; NASA Scout Program; radiation; turbulence; clouds; fog; dust
Received 27 November 2008; Revised 29 April 2010; Accepted 4 May 2010; Published online in Wiley Online Library 3 August 2010

Citation: Savijärvi H, Määttänen A. 2010. Boundary-layer simulations for the Mars Phoenix lander site. Q. J. R. Meteorol. Soc. 136: 1497-1505. DOI:10.1002/qj.650
\end{abstract}

\section{Introduction}

The Phoenix polar lander of the NASA Scout Program ('Following the water') touched down on the northern low plains of Mars at $234.25^{\circ} \mathrm{E}, 68.22^{\circ} \mathrm{N}$ on 26 May 2008. It operated successfully for 151 Martian solar days (sols, 1 sol $=24 \mathrm{~h} 40 \mathrm{~min}$ ). Phoenix landed in the relatively moist Martian early arctic summer, where the seasonal polar cap of $\mathrm{CO}_{2}$ and $\mathrm{H}_{2} \mathrm{O}$ ice sublimates to the air. The touchdown took place at $L_{\mathrm{S}}=78^{\circ}$, about 30 sols before the northern summer solstice where the solar longitude $L_{\mathrm{s}}$ (the seasonal index) is $90^{\circ}$.
The Phoenix mission was headed by the Lunar and Planetary Laboratory of the University of Arizona (Smith et al., 2009) with the atmospheric observations coordinated by the Canadian Space Agency (Whiteway et al., 2009). These consisted of thin-wire sensor temperatures at about 2, 1.5 and $1.25 \mathrm{~m}$ heights from the surface, surface pressures via a capacitive sensor, winds at $2 \mathrm{~m}$ from a hanging 'telltale' device observed by a camera, and backscattering from the dust and ice particles in the air by a dualwavelength light detection and ranging instrument (LIDAR). A thermal and electrical conductivity probe (TECP) measured properties of the sand-like topsoil (regolith), 
including the first in situ humidity measurements on Mars (Zent et al., 2010).

Phoenix did detect ground frost and underground ice and also, later in the mission, water ice fogs, water ice clouds and even weak snowfall streaks from clouds (Smith et al., 2009; Whiteway et al., 2009). We aim here to chart the diurnal boundary-layer properties at the Phoenix site using a column numerical model and to compare with observations now publicly available in the Planetary Data System of NASA. Special attention is given to the moisture cycle and its meteorological simulation and interpretation.

The University of Helsinki one-dimensional Mars model (UH 1D) has been used previously to study the local boundary layer in the low- and midlatitude lander sites (Viking 1 and 2: Savijärvi, 1991, 1995; Pathfinder: Savijärvi et al., 2004; Mars Exploration Rovers: Savijärvi and Kauhanen, 2008). Here the model is applied at the highlatitude Phoenix site, contrasting the diurnal cycle around $L_{\mathrm{s}}=90^{\circ}$ ( $\left.\mathrm{sol} 30\right)$ with a later period $\left(L_{\mathrm{s}}=122^{\circ}\right.$, sol 99) when the temperatures have started to decrease due to the approaching arctic autumn with frost, fog and clouds being observed. The diurnal evolution of the dust concentration and slope winds are also briefly discussed.

\section{The model and the environmental conditions}

The UH $1 \mathrm{D}$ is a hydrostatic column model forced by a constant geostrophic wind $V_{\mathrm{g}}$. The predicted surface net energy flux $G(t)$ drives the surface temperature evolution $T_{\mathrm{g}}$ via heat diffusion in the ground. The model equations are given in Savijärvi (1999); the $u$ and $\theta$ equations are discussed in section 4. Physical parametrizations include turbulence, radiation and cloud and dust physics. Turbulence is based on a Monin-Obukhov-type lowest layer and Blackadar approach aloft with an asymptotic mixing length of $300 \mathrm{~m}$. The emissivity long-wave (LW) and improved two-stream short-wave (SW) radiation schemes, the associated orbital algorithms and comparisons with line-by-line results are described in Savijärvi et al. (2004, 2005). The cloud physics are described below and the dust physics in section 4 . The present model version is the same as used for the diurnal and annual simulations at the two Mars Exploration Rover sites in Savijärvi and Kauhanen (2008), with the following refinements:

(1) In the stable boundary layer with Richardson numbers $R i>0$, the stability factor $f(R i)$ for the turbulent diffusion and surface transfer coefficients $K_{\mathrm{m}}, K_{\mathrm{h}}, C_{\mathrm{d}}$, $C_{\mathrm{h}}$ is

$$
f(R i)=\left(1+5 R i+44 R i^{2}\right)^{-2} .
$$

The formulation follows from the asymptotic theory, matches the Earth observations at midlatitudes as well as over the Arctic sea-ice, and produces good simulations in the extremely stable conditions of the Antarctic polar night (Savijärvi, 2009). As conditions can also become extremely stable during the cold Martian nights, a good local formulation for $f(R i)$ may be beneficial.

(2) The five-point Crank-Nicholson ground diffusion scheme applies non-dimensional depths $z^{\prime}=z / H_{\mathrm{g}}$, $H_{\mathrm{g}}$ being the scale height of the diurnal wave in $T_{\mathrm{g}}$. Optimal depths $z^{\prime}$ were determined by forcing the surface with a diurnal $50 \mathrm{~W} \mathrm{~m}^{-2}$ square wave $G$ and minimizing the error in $T_{\mathrm{g}}$; they turned out to be $0,0.08,0.17,0.63$ and 1.78 (with maximum error in $T_{\mathrm{g}}<0.5 \mathrm{~K}$ for the Phoenix site thermal properties defined later). The fixed physical depths previously used have also been quite close to optimal, set siteby-site via a similar process (Savijärvi, 1992) but the use of $z^{\prime}$ simplifies the process and guarantees the same high relative accuracy for all sites or grid points, irrespective of their possibly very different thermal properties. At the lowest point, well below $H_{\mathrm{g}}$, the temperature $\left(T_{\text {deep }}\right)$ is kept constant in the present short integrations.

(3) The moist parametrizations are similar to those used in numerical weather prediction. Specific humidity $q$ and mixing ratio of water ice $q_{\mathrm{i}}$ are the predicted variables. Turbulence diffuses them vertically and the ice crystals are subject to sedimentation at velocity $w_{\mathrm{i}}$. Frost forms on the ground during supersaturation, i.e.

$$
E_{0}=\rho C_{h} V\left\{q_{\text {sat }}\left(p_{s}, T_{\mathrm{g}}\right)-q\right\} \beta<0,
$$

(with $\beta=1$, and density $\rho$, wind $V$ and $q$ referring to the lowest air level), while sublimation $E_{0}>0$ releases ice to the air, constrained by the topsoil ice availability $\beta<<1$ in such a way that the column precipitable water content $P W C=\Sigma q \Delta p / g$ matches observations. For Mars

$$
q_{\mathrm{sat}}(p, T)=\frac{0.41 e_{\mathrm{sat}, \mathrm{i}}}{p-0.59 e_{\mathrm{sat}, \mathrm{i}}},
$$

and the water vapour saturation pressure $(\mathrm{hPa})$ with respect to ice is

$$
e_{\text {sat }, \mathrm{i}}(T)=6.1135 \exp \frac{22.542(T-273.16)}{T+0.32}
$$

(Buck, 1981). If after a time step the relative humidity $R H=q / q_{\text {sat }}(p, T)$ of any air layer exceeds the critical $R H$ for heterogeneous nucleation onto dust $(120 \%$, based on calculations for Pathfinder, Määttänen et al., 2005), the extra vapour condenses to $q_{\mathrm{i}}$, while in subsaturated conditions the existing extra $q_{\mathrm{i}}$ sublimates back to vapour, with latent heat effects included both ways (Haltiner and Williams, 1980). High ice clouds, which are rare for the latitude and season according to the Mars Global Surveyor Thermal Emission Spectrometer (MGS/TES) observations, are not included.

(4) The cloud-radiation interaction follows the cirrus ice crystal parametrization of Ebert and Curry (1992): thus for an ice water path $I W P=\Sigma q_{\mathrm{i}} \Delta p / g\left(\mathrm{gm}^{-2}\right)$ and effective radius $r_{\mathrm{e}}(\mu \mathrm{m})$, the emissivity is $\varepsilon_{\mathrm{i}}=1-\exp \left(-1.6 I W P / r_{\mathrm{e}}\right)$ and the SW optical depth, $\tau_{\mathrm{i}}=2.431^{s} I W P / r_{\mathrm{e}}$. The SW ice single-scattering albedo and asymmetry parameter are 0.999 and 0.78 , while for the dust particles 0.94 (Määttänen et al., 2009, Wolff et al., 2009) and 0.70 are adopted. The value of $w_{\mathrm{i}}, 0.14 \mathrm{~m} \mathrm{~s}^{-1}$, is based on the LIDARobserved slow fall rate of the ice cloud base during sol 99 (Whiteway et al., 2009). This implies a radius of about $25 \mu \mathrm{m}$ for the sedimenting particles (Taylor et al., 2007) so $25 \mu \mathrm{m}$ is tentatively adopted for the $r_{\mathrm{e}}$ of the ice crystals. 
The present model version includes 28 air levels up to $28 \mathrm{~km}$ height with the lowest levels being at $0.3,1,2,7$ and $20 \mathrm{~m}$ above the ground. Based on the MGS mappings, the site surface albedo is set to 0.18 and the thermal inertia to $150 \mathrm{~J} \mathrm{~m}^{-2} \mathrm{~s}^{-0.5} \mathrm{~K}^{-1}$. With the volumetric heat capacity of the ground assumed $0.8 \times 10^{6} \mathrm{~J} \mathrm{~m}^{-3} \mathrm{~K}^{-1}$, this gives $H_{\mathrm{g}}$ of $3.14 \mathrm{~cm}$. The roughness length is set to $2 \mathrm{~cm}$ and the $V_{\mathrm{g}}$ to $10 \mathrm{~m} \mathrm{~s}^{-1}$, producing $2 \mathrm{~m}$ wind speeds of 4 to $6 \mathrm{~m} \mathrm{~s}^{-1}$, as typically observed by the telltale. The Mars Limited-Area Model (MLAM) and the UK Mars General Circulation Model (MGCM) simulations for the Phoenix landing also indicated free-atmosphere wind speeds of 8 to $10 \mathrm{~m} \mathrm{~s}^{-1}$ (Kauhanen et al., 2008). The initial surface pressure $p_{\mathrm{s}}$ is from observations, as are the dust and moisture values. The dust SW optical depth $\tau_{\text {dust }}$ is assumed to decay exponentially upwards with a scale height of $11.3 \mathrm{~km}$ and $q(z)$ is initialized using such a constant relative humidity that the $P W C$ matches the observed values. The model starts at 0000 true local solar time (LT) with a time step of $10.27 \mathrm{~s}$ and keeps repeating its diurnal cycle if the main external factors $L_{\mathrm{s}}, p_{\mathrm{s}}, V_{\mathrm{g}}, \tau_{\text {dust }}, T_{\text {deep }}$ are not changed.

\section{Results for $L_{\mathrm{s}}=90^{\circ}$}

The diurnal cycle is first studied around the summer solstice $\left(L_{\mathrm{s}}=90^{\circ}\right.$, sol 30) when the sun does not set on the Phoenix site at $68^{\circ} \mathrm{N}$ (the Polar Circle is at $64.7^{\circ} \mathrm{N}$ on Mars). The initial surface pressure, $P W C$ and $\tau_{\text {dust }}$ are set to the observed $8.17 \mathrm{hPa}, 30 \mu \mathrm{m}$ and 0.6 (Tamppari et al., 2010). Figure 1 displays all the observed fast-response $(2 \mathrm{~s}) 2 \mathrm{~m}$ temperatures for sols 29.5 to 33 , together with the model values for the ground ( $T_{\mathrm{g}}$, dotted line), at $2 \mathrm{~m}$ ( $T_{2 \mathrm{~m}}$, solid line), and at $1200 \mathrm{~m}$ (dashed line), with $V_{\mathrm{g}}$ being $10 \mathrm{~m} \mathrm{~s}^{-1}$. The observed diurnal cycle is quite repetitive with the model's $T_{2 \mathrm{~m}}$ being in the middle of the rapidly varying turbulent $T_{2 \mathrm{~m}}$ observations during the day, and close to the steadier, less turbulent, observed evolution during the night. The afternoon maxima reach $260 \mathrm{~K}$ at the ground and $243 \mathrm{~K}$ at $2 \mathrm{~m}$ while the night-time minima (at $0200 \mathrm{LT}$ ) are about $193 \mathrm{~K}$ and $196 \mathrm{~K}$, respectively. The diurnal amplitude is much smaller at $1200 \mathrm{~m}$ with a phase lag of several Mars hours. The model's $2 \mathrm{~m}$ temperature starts to decrease after the 1500 LT maximum, while the observed $T_{2 \mathrm{~m}}$ tends to remain high until $T_{\mathrm{g}}$ drops below it (at about $1700 \mathrm{LT}$ ), which cuts off convection.

Figures 1(b) and (c) display the same but with $V_{\mathrm{g}}$ of 1 and $30 \mathrm{~m} \mathrm{~s}^{-1}$ in the model, respectively. The figures show that the temperatures are only weakly sensitive to the wind speed. The strong wind case indicates temperatures which are slightly too high, while the weak winds are associated with temperatures too low compared with the observed $T_{2 \mathrm{~m}}$, but the differences are small. The reason for the low sensitivity of $T_{2 \mathrm{~m}}$ and $T_{\mathrm{g}}$ to wind speed is seen in Figure 2, which shows the model's surface energy fluxes (for $V_{\mathrm{g}}=10 \mathrm{~m} \mathrm{~s}^{-1}$ ). They demonstrate the midnight sun in the net solar radiation $S W_{\text {net }}$ and the overwhelming dominance of radiation in the net energy flux into the ground $G=S W_{\text {net }}+L W_{\text {net }}-H_{\mathrm{o}}-L E_{\mathrm{o}}$, the winddependent sensible heat flux $H_{\mathrm{o}}=\rho C_{\mathrm{p}} C_{\mathrm{h}} V\left(T_{\mathrm{g}}-T\right)$ being quite small due to the small air density on Mars (and the latent heat flux $L E_{\mathrm{o}}$ being even smaller). The net radiation and $G$ are negative between about 1700 LT and 0400 LT. At about $1830 \mathrm{LT}, H_{\mathrm{o}}$ turns negative with convective conditions returning at about $0500 \mathrm{LT}$.
At about 2100 LT the ground has reached the frost point and weak ground frost formation takes place in the model, peaking at around midnight. The model's $2 \mathrm{~m}$ relative humidity is less than $5 \%$ during daytime but it increases rapidly in the evening, in accordance with the TECP findings (Zent et al., 2010). The $2 \mathrm{~m}$ water vapour pressure $e_{2 \mathrm{~m}}$ drops rapidly in the evening and is small in the model during the coldest hours (below $0.1 \mathrm{~Pa}$ ), as by TECP, but during daytime $e_{2 \mathrm{~m}}$ is underestimated $(0.66$ versus $1.8 \mathrm{~Pa})$ for that value of $\beta(0.03 \%)$ which preserves the afternoon $P W C$ at $30 \mu \mathrm{m}$ in the model, as observed at around sol 30 . This indicates that the frost formation removes moisture correctly from the air in the model, but the sublimation of ice adsorbed by the regolith may be ineffective in its present simple formulation, or local 3D daytime effects not seen by the $1 \mathrm{D}$ approach may contribute. These aspects will be considered in further studies.

Temperature profiles are displayed in Figure 3 for Martian hours $0400,1000,1700$ and 2200 LT. A strong $20 \mathrm{~K}$ surface inversion to about $500 \mathrm{~m}$ height is indicated at $0400 \mathrm{LT}$ while at 1000 LT a rapidly growing convective boundary layer extends to $1.5 \mathrm{~km}$ with a strongly superadiabatic surface layer, as observed by the rovers (Smith et al., 2004). During late afternoon (1700 LT) the well-mixed layer extends to $4 \mathrm{~km}$. The air then cools toward the night-time inversion. Even above the boundary layer the temperature profiles display a diurnal cycle, SW and LW absorption (by dust and $\mathrm{CO}_{2}$ ) dominating when the sun is high, and net thermal emission to space (by dust, $\mathrm{CO}_{2}$ and water vapour) during low sun and darkness. The moisture profiles (not shown) display nearly constant values of $q$ (about $0.3 \mathrm{~g} \mathrm{~kg}^{-1}$ or $300 \mathrm{ppmm}$ ) up to $4 \mathrm{~km}$ height. During the night hours some moisture is removed near the surface into ground frost and thin fog. Sublimation and convection then drive the moisture vigorously back into the rapidly growing wellmixed convective layer.

In our $L_{\mathrm{S}}=90^{\circ}$ simulations, ice clouds did not appear nor were they observed at this time by Phoenix. However, a very thin ice fog $(I W P=0.05 \mu \mathrm{m})$ develops in the model between 0030 and $0330 \mathrm{LT}$ with $q_{\mathrm{i}}$ reaching $40 \mathrm{ppmm}$ at $2 \mathrm{~m}$ by $0200 \mathrm{LT}$. The fog extends up to $50 \mathrm{~m}$. The fog/cloud aspects are discussed more thoroughly in section 5 but, as a preparation, the critical saturation ratios $S_{\text {nucl }}$ were calculated with a detailed nucleation scheme (Määttänen et al., 2005; Vehkamäki et al., 2007) for heterogeneous water ice nucleation to activate onto $1 \mu \mathrm{m}$ radius dust particles in $\mathrm{CO}_{2}$ gas, using as input the Phoenix sol $30 p, T, q$ profiles at $0200 \mathrm{LT}$ and at $1500 \mathrm{LT}$. The resulting $S_{\text {nucl }}$ was 1.35 to 1.43 at all heights, so one may note that for day and night alike, the typical critical relative humidity for fog and cloud formation is about $135-140 \%$ in the summer conditions at Phoenix, not unlike for cirrus clouds on the Earth. In section 5 the range $100-150 \%$ for $R H_{\text {crit }}$ is studied.

\section{Slope wind and dust evolution experiments for $L_{\mathrm{s}}=90^{\circ}$}

The Phoenix telltale observations for sols 0 to 50 (Figure 4) indicate $2 \mathrm{~m}$ winds which are 4 to $6 \mathrm{~m} \mathrm{~s}^{-1}$, easterly during the night and westerly in the afternoon. They appear to veer throughout the sol. A veering wind pattern was also observed by the Viking Lander 2 (on an $0.1^{\circ}$ slope at $48^{\circ} \mathrm{N}$ ) during each summer, when the thermal forcing is strong and the large-scale wind is weak (Leovy, 1982). Also 

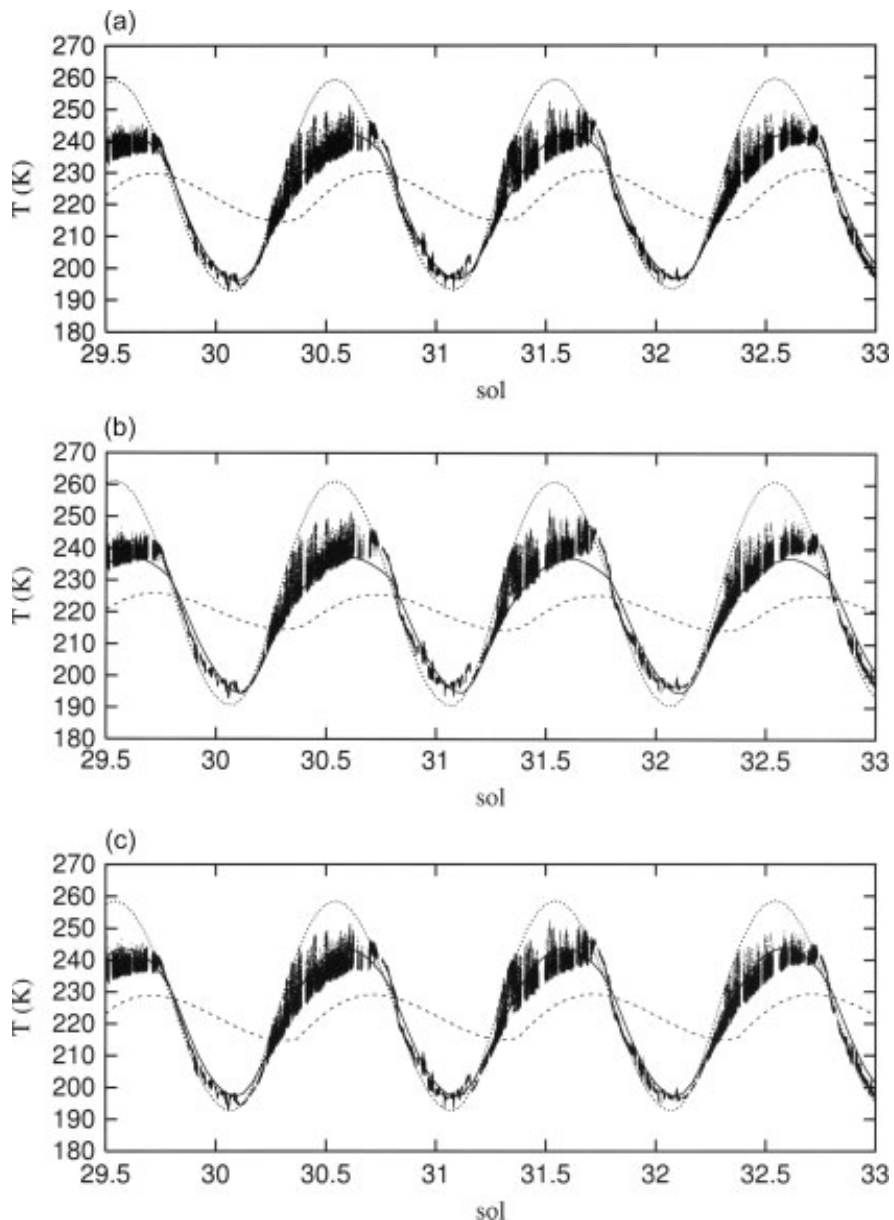

Figure 1. Observed $2 \mathrm{~m}$ (dots) and modelled $2 \mathrm{~m}$ (solid line), ground (dotted line) and $1200 \mathrm{~m}$ (dashed line) temperatures for Phoenix sols 29.5 to 33 $\left(L_{\mathrm{s}}=90\right.$ to $\left.91^{\circ}\right) . V_{\mathrm{g}}$ is (a) $10 \mathrm{~m} \mathrm{~s}^{-1}$, (b) $1 \mathrm{~m} \mathrm{~s}^{-1}$, and (c) $30 \mathrm{~m} \mathrm{~s}^{-1}$.

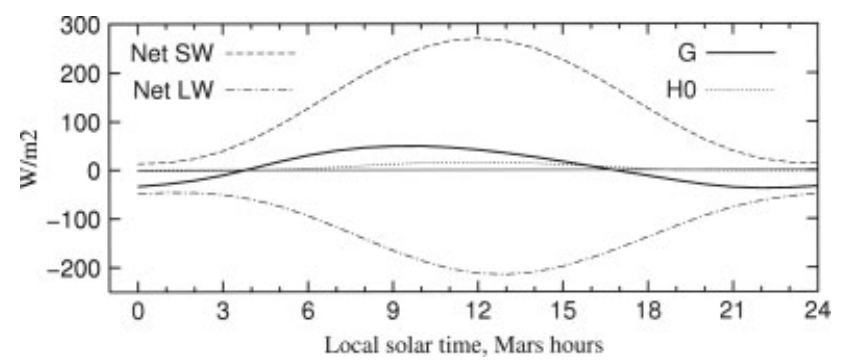

Figure 2. Surface energy fluxes for the Phoenix site at $L_{\mathrm{s}}=90^{\circ}$ from the sol 30 simulation. $H_{\mathrm{o}}$ is the sensible heat flux, and $G$ the net energy flux from the atmosphere to the ground.

the MLAM simulations for the Phoenix landing indicated veering upslope-downslope diurnal winds superposed on an easterly basic flow (Kauhanen et al., 2008). Although the topography around Phoenix is certainly more complex than just a local slope at an angle $\alpha$, we tested whether adding a simple Prandtl slope wind mechanism (Atkinson, 1981) would bring about a realistic veering pattern. A buoyancy forcing term was hence added to the $1 \mathrm{D}$ model's $u$ equation:

$$
\frac{\partial u}{\partial t}=f\left(v-v_{g}\right)+g \frac{\left(\theta-\theta_{0}\right)}{\theta_{0}} \sin \alpha+\frac{\partial}{\partial z}\left(K_{m} \frac{\partial u}{\partial z}\right)
$$

where $\theta_{0}$ represents the undisturbed potential temperature and the upslope is to an arbitrary $x$. $\theta_{\mathrm{o}}$ was set to $225 \mathrm{~K}$ for air undisturbed by the surface at about $1.2 \mathrm{~km}$ height (Figures 1

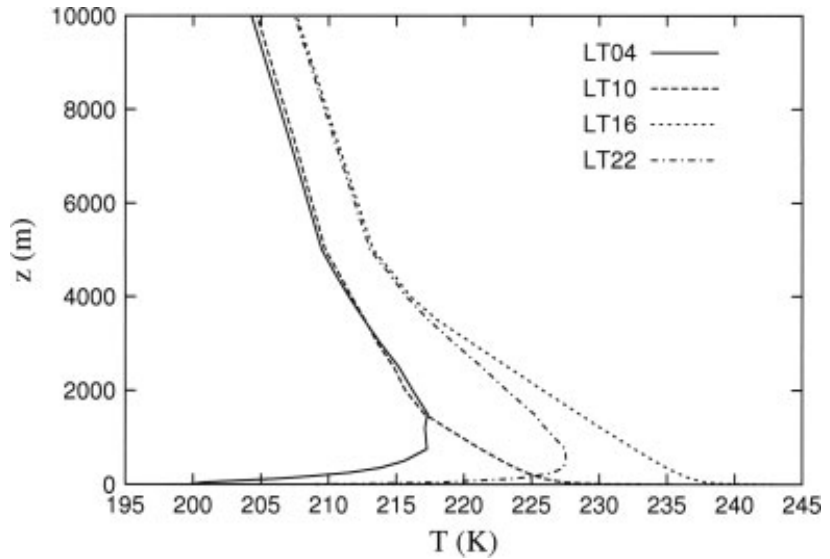

Figure 3. Temperature profiles for the Phoenix site at $L_{\mathrm{s}}=90^{\circ}$ at 0400 , 1000, 1600 and 2200 LT from the sol 30 simulation.

and 3). The forcing was set to zero above $1.2 \mathrm{~km}$. The resulting upslope (downslope) wind component $u$ induces adiabatic cooling (heating) in the $\theta$ equation through vertical motion $w=u \sin \alpha$,

$$
\frac{\partial \theta}{\partial t}=-S u \sin \alpha+\frac{\partial}{\partial z}\left(K_{h}\left\{\frac{\partial \theta}{\partial z}-\gamma\right\}\right)+Q_{\mathrm{rad}}
$$

with the basic state stability $S=\mathrm{d} \theta_{\mathrm{o}} / \mathrm{d} z=3.5 \mathrm{~K} \mathrm{~km}^{-1}$ (Figure 3). The coupled system was first checked numerically by setting $K$ to a constant and $f=\gamma=Q_{\text {rad }}=0$. This 
(a)

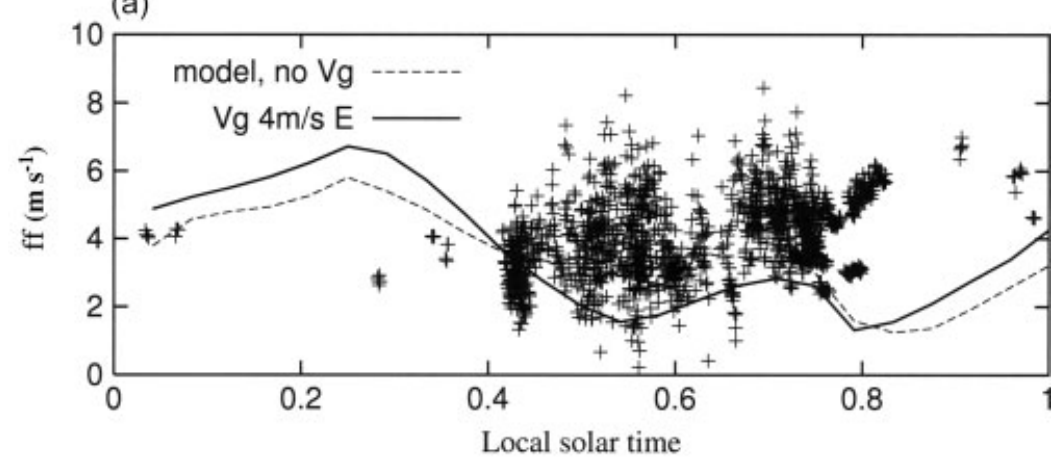

(b)

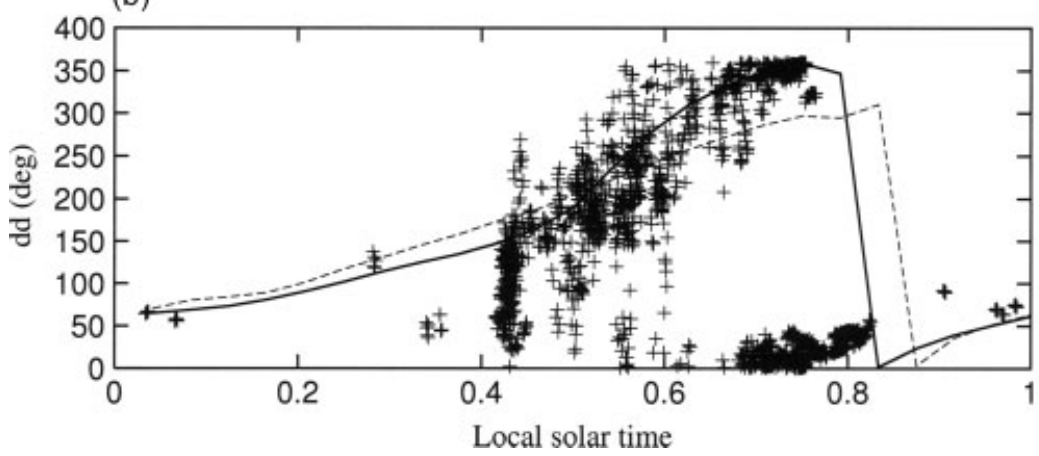

Figure 4. Phoenix 'telltale' observations (crosses) of (a) wind speed and (b) wind direction for sols 0 to 50 and the slope wind model results for $V_{\mathrm{g}}=0$ (dashed lines) and $V_{\mathrm{g}}=4 \mathrm{~m} \mathrm{~s}^{-1}$ from east (solid lines).

resulted in the analytic Prandtl solution discussed for Mars in Savijärvi and Siili (1993).

The full model with the slope terms and $\alpha=0.3^{\circ}, V_{\mathrm{g}}=0$ produced practically the same temperatures as in section 3 , the surface winds now veering throughout the sol with upslope winds in the afternoon and downslope winds during the night hours, turned to the right by the relatively strong Coriolis force at $68^{\circ} \mathrm{N}$. When the upslope is directed to the north-east, the wind directions resemble those observed (dashed lines in Figure 4). If a weak $4 \mathrm{~m} \mathrm{~s}^{-1}$ easterly basic flow $V_{\mathrm{g}}$ is added (based on the GCM mean values for the season and latitude; Read and Lewis, 2004), the wind directions improve (solid lines in Figure 4) although the wind speeds are somewhat high in the late morning, and weak during the afternoon and early evening. It thus appears that the midsummer winds at Phoenix are mainly local slope winds superimposed on a weak easterly basic flow of the season.

A simple bulk dust scheme was also tested by coupling the evolving dust concentration $n(z, t)$ into the model via

$$
\frac{\partial n}{\partial t}=w_{\mathrm{d}} \frac{\partial n}{\partial z}+\frac{\partial}{\partial z}\left(K_{h} \frac{\partial n}{\partial z}\right)+S_{n}
$$

after Taylor et al. (2007). The effective radius $r_{\mathrm{e}}$ of the airborne mineral dust particles is assumed $1.6 \mu \mathrm{m}$, implying a sedimentation velocity $w_{\mathrm{d}}$ of $2 \mathrm{~mm} \mathrm{~s}^{-1}$ (Taylor et al., 2007). The dust optical depth is now obtained 'dynamically', via the vertical integration of the evolving $n$ :

$$
\tau_{\text {dust }}(z, t)=c \int_{z}^{\infty} n\left(z^{\prime}, t\right) \mathrm{d} z^{\prime},
$$

with the extinction coefficient $\mathrm{c}$ of $1.61 \times 10^{-11} \mathrm{~m}^{2}$, assuming a Mie SW extinction factor $Q_{e}$ of 2 (the 'large particle' approximation) and $c \approx Q_{\mathrm{e}} \pi r_{\mathrm{e}}^{2}$. The concentration was set to $n=n_{\mathrm{o}} \exp (-z / H)$ initially. With $n_{\mathrm{o}}=3.34 \times 10^{6}$ particles $\mathrm{m}^{-3}$ and $H=11.3 \mathrm{~km}$, this produces the same dust SW optical depth profile as used in section 3. Sedimentation now removes the dust particles all the time but quite slowly (the e-decaying time is about 65 sols, as also shown by the Viking lander data after the great dust storms). On the other hand, convective mixing is very effective during daytime. Hence $n(z, t)$ quickly reaches a well-mixed value (about $2.9 \times 10^{6}$ particles $\mathrm{m}^{-3}$ ) up to $4 \mathrm{~km}$ height which then remains overnight with little sedimentation. The LIDAR on board Phoenix detected the associated kink at $4 \mathrm{~km}$ in the $532 \mu \mathrm{m}$ optical extinction coefficient (Whiteway et al., 2009). The feedback to the temperatures is however weak, as the integration over $z$ to get $\tau_{\text {dust }}(z, t)$ smooths out the kinks from the latter, so the model temperatures are insensitive to details in $n(z)$ and are practically the same as shown in section 3 for the fixed $\tau_{\text {dust }}$.

The local dust source $S_{\mathrm{n}}$ is absent in the present experiments since the surface winds are too weak to raise dust. A minimum friction velocity of 1 to $1.3 \mathrm{~m} \mathrm{~s}^{-1}$ is needed to raise dust (Taylor et al., 2007); this converts to $2 \mathrm{~m}$ wind speed of 12 to $15 \mathrm{~m} \mathrm{~s}^{-1}$. However we note that, although the observed mean wind speeds at Pathfinder were typically only 4 to $6 \mathrm{~m} \mathrm{~s}^{-1}$, as with Phoenix, there were many $4 \mathrm{~s}$ convective gusts in the Pathfinder fast-response wind data exceeding 12 to $15 \mathrm{~m} \mathrm{~s}^{-1}$ every sol (cf. Figure 1 of Savijärvi et al., 2004). Therefore some dust could be raised locally during each sol and perhaps a statistical scheme should be devised to relate gust to $S_{\mathrm{n}}$. Dust devils are extreme cases of such gusts and they were observed occasionally around Phoenix. 


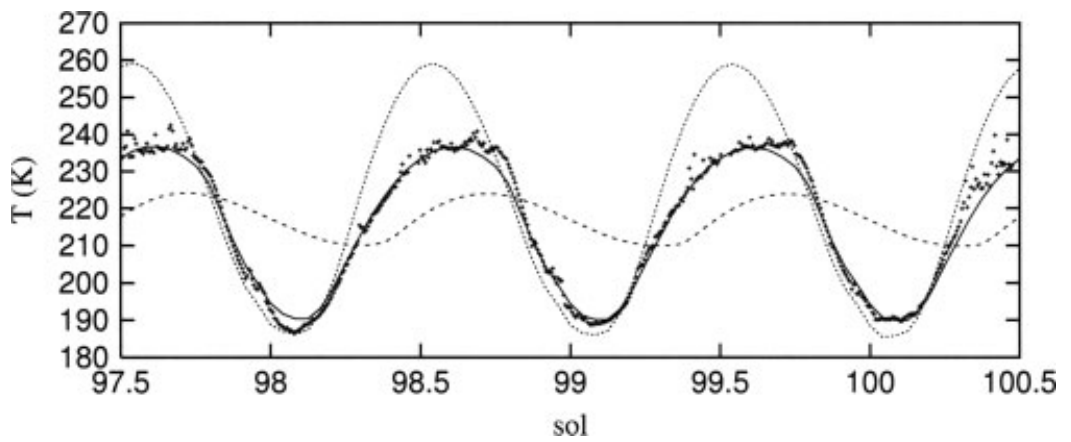

Figure 5. Observed $2 \mathrm{~m}$ mean temperature over $512 \mathrm{~s}$, and modelled $2 \mathrm{~m}$ (solid), ground (dots) and $1200 \mathrm{~m}$ (dashed) temperatures for Phoenix sols 97.5 to $100.5\left(L_{\mathrm{s}}=121\right.$ to $\left.122^{\circ}\right) . V_{\mathrm{g}}$ is $10 \mathrm{~m} \mathrm{~s}^{-1}$.

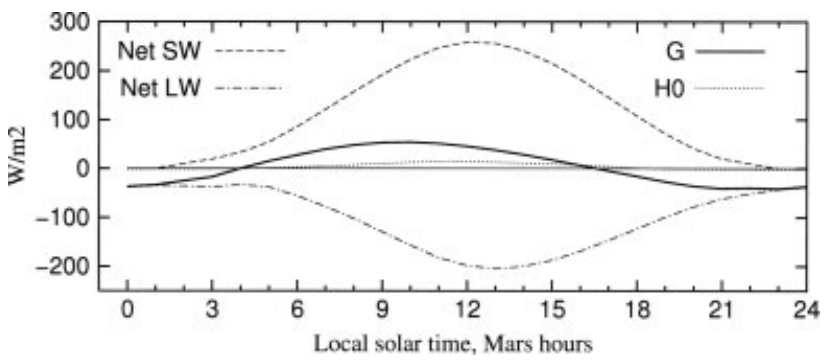

Figure 6. Surface energy fluxes for Phoenix $\left(L_{\mathrm{s}}=122^{\circ}\right)$ from the sol 99 simulation.

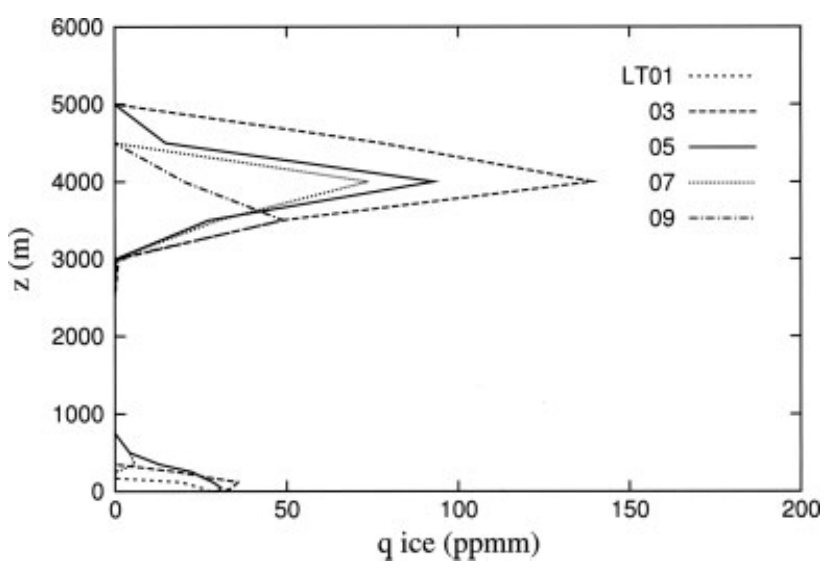

Figure 7. Ice mixing ratio profiles for Phoenix $\left(L_{\mathrm{s}}=122^{\circ}\right)$ during the morning hours from the sol 99 simulation.

\section{Results for $L_{\mathrm{s}}=122^{\circ}$}

Clouds, fog and ground frost were reported almost every night by Phoenix from about sol 80 onward, as the temperatures started to drop toward the arctic autumn. The LIDAR famously detected ice clouds and even snowfall at about 3-4 km height in the morning of sol 99 . Here we apply the moist $1 \mathrm{D}$ model around sol 99, $L_{\mathrm{s}}=122^{\circ}$. The initial surface pressure of $7.56 \mathrm{hPa}, \tau_{\text {dust }} 0.3$ and $P W C$ $40 \mu \mathrm{m}$ are from observations (Tamppari et al., 2010) while the initial temperature profile is based on the MGS/TESderived mean values for the latitude and season (Read and Lewis, 2004). This is the wettest time of the year at $68^{\circ} \mathrm{N}$, since the midnight sun has driven most of the water ice off the winter polar cap into the atmosphere. Accordingly, the constant air relative humidity in initializing the $P W C$ is $65 \%$, and the topsoil ice availability for sublimation $(\beta)$ has to be $0.3 \%$, ten times more than in the solstice simulation, to maintain the afternoon $P W C$ at about $40 \mu \mathrm{m}$ from sol to sol, as was observed from orbit, against the strong removal of moisture to ground frost each night.

Figure 5 shows the temperatures for the sols 97.5-100.5. The observed $T_{2 \mathrm{~m}}$ now consists of $512 \mathrm{~s}$ means, so the rapid turbulent variations (like those in Figure 1) are averaged out. The repetitive diurnal $T_{2 \mathrm{~m}}$ is well simulated except during the late afternoon, when it again drops faster than observed. The temperatures are slightly lower than in Figure 1. The net surface SW flux (Figure 6) now indicates midnight darkness, after which the net SW flux increases only slowly, while the weakly negative net LW flux stays nearly constant. These are indications of morning fog and cloud. The formation of ground frost already starts at 2000 LT in the simulation. It peaks at $2200 \mathrm{LT}$ and the associated latent heat addition $\left(0.1 \mathrm{~W} \mathrm{~m}^{-2}\right)$ to $G$ is able to cause a visible upward kink in the model $T_{\mathrm{g}}$ in Figure 5. This is transferred to $T_{2 \mathrm{~m}}$ and can be detected also in the observed $T_{2 \mathrm{~m}}$ every evening.

Figure 7 displays the morning profiles of $q_{\mathrm{i}}$ during the simulated sol 99. Shallow radiation fog exists already at about 0100 LT near the surface and grows; by 0500 LT the fog extends to $800 \mathrm{~m}$. By $0700 \mathrm{LT}$ it lifts off the ground, which is heated by the increasing solar radiation. An ice cloud layer is formed at $4 \mathrm{~km}$ by $0300 \mathrm{LT}$. It then lowers slowly to 3-4 km and stays until 1030 LT. The cloud marks the top of the moist residual convective layer (Figure 8) which cools to supersaturation by LW radiation (Figure 9). The LIDAR recorded the thickest cloud layer at about $3.7 \mathrm{~km}$ at 0430-0530 LT on sol 99 (Whiteway et al., 2009), with fog below $1 \mathrm{~km}$ and snowfall streaks from the cloud base at $3.4 \mathrm{~km}$. The $532 \mu \mathrm{m}$ optical extinction coefficient derived from the LIDAR signal peaked to $0.13 \mathrm{~km}^{-1}$ at $3.7 \mathrm{~km}$ at $0500 \mathrm{LT}$ (dust + cloud) and was about $0.03 \mathrm{~km}^{-1}$ at 1 to $2.5 \mathrm{~km}$ (dust only) (Whiteway et al., 2009), while the SW extinction coefficient $(\mathrm{d} \tau / \mathrm{d} z)$ is $0.11 \mathrm{~km}^{-1}$ at $3750 \mathrm{~m}$ and $0.027 \mathrm{~km}^{-1}$ at 1 to $2.5 \mathrm{~km}$ in our simulation.

Figure 8 shows the model's specific humidity profiles (q) at $0400,1000,1600$ and 2200 LT. The 1000 LT and 1600 LT profiles indicate sublimation from the surface. In the afternoon and evening $q$ is well-mixed to $4.5 \mathrm{~km}$, ground frost formation eroding it near the surface at 2200 LT. The 0400 LT profile implies strong removal to cloud at 3 to $4.5 \mathrm{~km}$, and to fog and frost at 0 to $600 \mathrm{~m}$. By $1000 \mathrm{LT}$ the fog is gone, and convection together with sublimation drives the moisture back into a rapidly growing new well-mixed layer, with some cloud still left aloft.

The temperature profiles are displayed in Figure 9. They demonstrate values 5 to $10 \mathrm{~K}$ cooler than during sol 30 (Figure 3). The convective dry-adiabatic layer extends to 


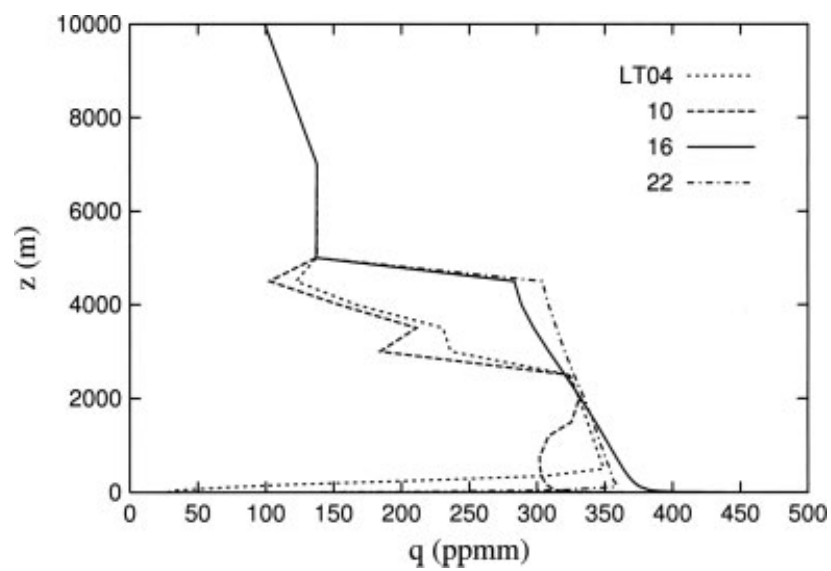

Figure 8. Specific humidity profiles for Phoenix $\left(L_{\mathrm{s}}=122^{\circ}\right)$ at 0400,1000 , 1600 and 2200 LT from the sol 99 simulation.

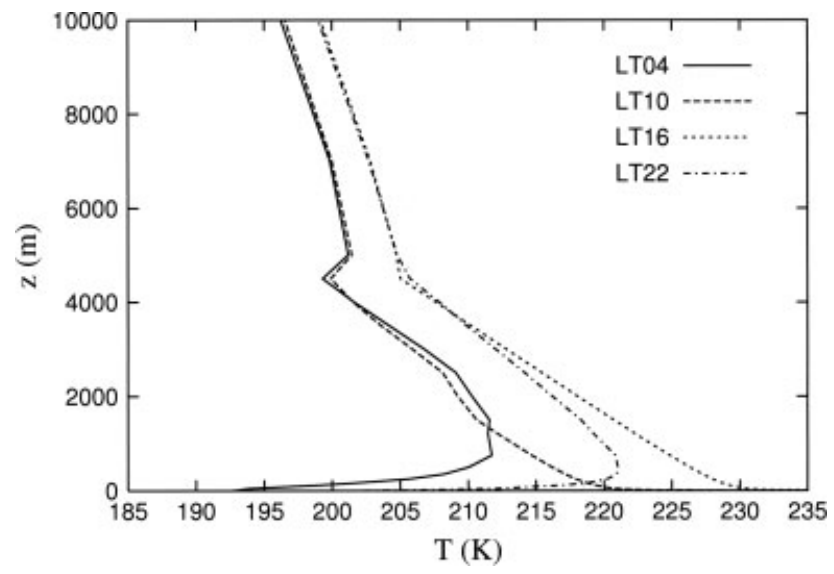

Figure 9. Temperature profiles for Phoenix $\left(L_{\mathrm{s}}=122^{\circ}\right)$ at $0400,1000,1600$ and 2200 LT from the sol 99 simulation.

$1.5 \mathrm{~km}$ by $1000 \mathrm{LT}$ and to $4.5 \mathrm{~km}$ by late afternoon, while a strong surface inversion prevails during the night. There is also an upper inversion at $4.5 \mathrm{~km}$ in the $0400 \mathrm{LT}$ and $1000 \mathrm{LT}$ profiles. This is due to the ice particle cloud-top cooling, with a nearly wet-adiabatic profile developing to the cloud layer below through weak latent heating effects. The cloud and fog, though thin, are thick enough to increase (decrease) the downwelling LW (SW) radiation at the surface (DLR, DSR), as noted in Figure 6. Quantitatively, at 0300 LT, when the ice amount is at its thickest (IWP $1.92 \mu \mathrm{m})$, DLR increases by $23 \%$ and DSR decreases by $16 \%$ from a simulation where the cloud and fog are kept transparent to radiation.

Sensitivity tests were also made on the ice cloud physics. The experiments have so far assumed that fresh ice formation onto the dust starts at $R H_{\text {crit }}$ of $120 \%$, with $R H_{\text {crit }} 100 \%$ thereafter, there then being ice-covered particles on which to nucleate. This is similar to (for example) the present ECMWF model formulation for cirrus. Figure 10 shows $q_{\mathrm{i}}$ as in Figure 7 , but having $R H_{\text {crit,initial }} 150 \%$ instead of $120 \%$. This delays the cloud formation, as can be expected, but the differences to Figure 7 are not dramatic. Figure 11 displays a simulation where the $R H_{\text {crit }}$ of $120 \%$ is extended to the existing cloud/fog, as has been common in cirrustype simulations in the past. It has also been observed in northern Finland that $R H_{\mathrm{i}}$ of 110 to $120 \%$ can sometimes be maintained in clear air with diamond dust (i.e. within a very thin ice cloud; Makkonen and Laakso, 2005). Figure 11 depicts an ice cloud which is perhaps too low and where the

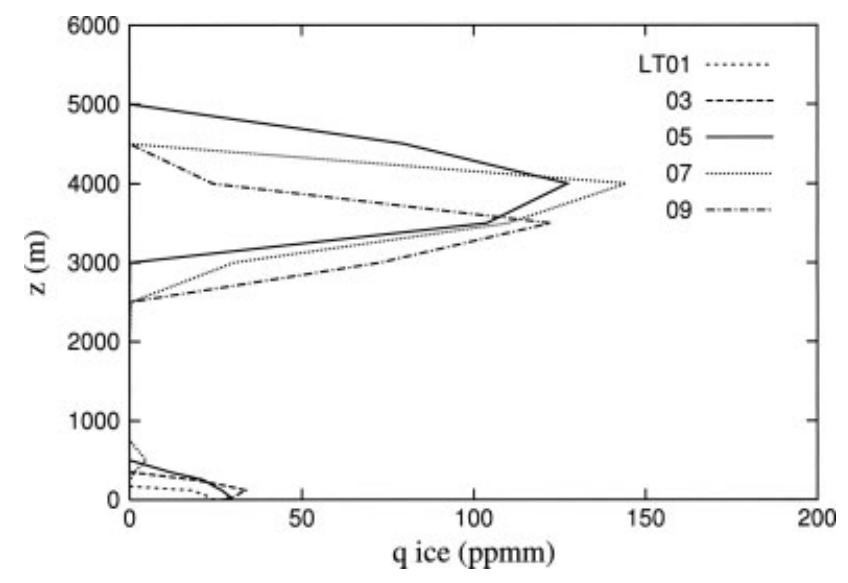

Figure 10. As Figure 7, but for $R H_{\text {crit,initial }}=150 \%$.

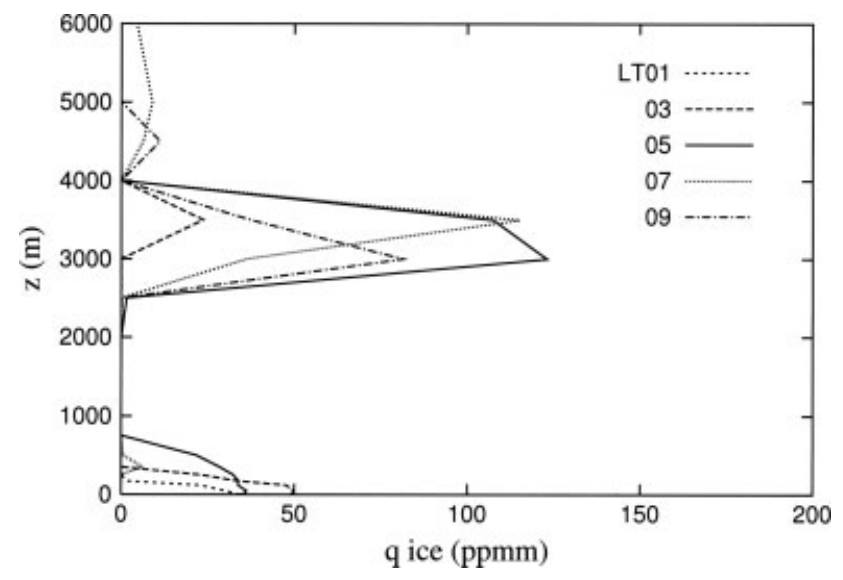

Figure 11. As Figure 7, but for $R H_{\text {crit }}=120 \%$ all the time.

fog is thicker than in Figure 7, but again the differences are not too dramatic.

Finally, Figure 12 shows a case where the $R H_{\text {crit }}$ is $100 \%$ for both on-dust and on-ice nucleation all the time. This clearly leads to clouds too early and at too high levels, compared with the LIDAR observations. One may deduce that the fog and boundary-layer cloud formation on Mars is not too sensitive to the triggering saturation ratio, but the ratio should be larger than 1 , about 1.2 to 1.5 . Further experiments (not shown) display strong sensitivity to the initial amount of moisture. This may explain the quite variable cloud observations from sol to sol at Phoenix as different air masses are advected past the site.

\section{Conclusions}

Diurnal simulations were made for the Phoenix lander site by applying a moist 1D boundary-layer model during the summer solstice (Phoenix sol 30) and at a later date (sol 99) and comparing with observations, in order to study the local thermodynamics of the polar summer boundary layer of Mars. The solstice simulations displayed $2 \mathrm{~m}$ temperatures close to those observed and depicted an afternoon convective layer to $4 \mathrm{~km}$ height, in which the moisture and dust concentrations are vertically well-mixed. A surface inversion occurs every night with ground frost around midnight and a thin radiation fog during the coldest hour (0200 LT). Winds at Phoenix appear to be local slope winds superimposed 


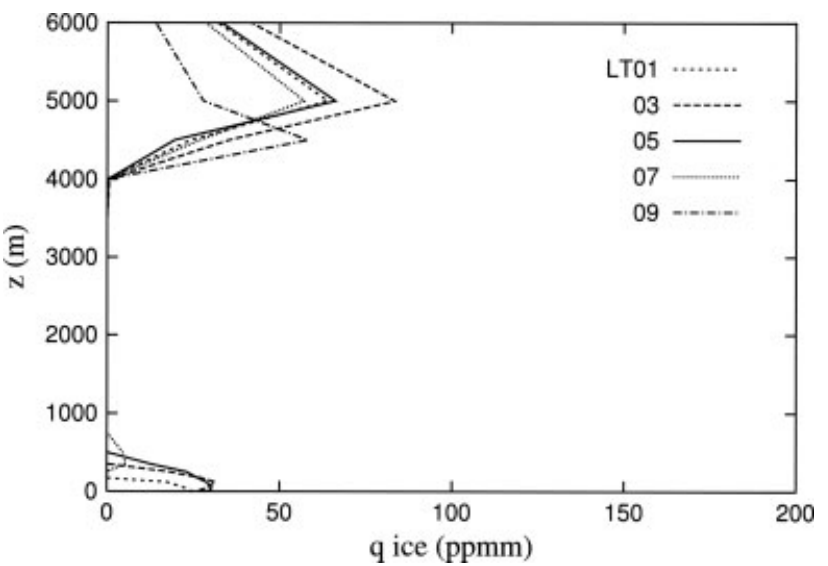

Figure 12. As Figure 7, but for $R H_{\text {crit }}=100 \%$ all the time.

on a weak easterly basic flow of the season. The simulated near-surface water vapour pressure is low $(<0.1 \mathrm{~Pa})$ and close to the in situ TECP observations during the night, but is underestimated ( 0.66 versus $1.8 \mathrm{~Pa})$ during daytime, where $3 \mathrm{D}$ effects may contribute.

The sol 99 simulation led to lower diurnal $2 \mathrm{~m}$ temperatures, again close to those observed. Strong frost formation peaks at $2200 \mathrm{LT}$ in the model, inducing weak but noticeable latent heat warming in the ground temperature, which transfers also to $T_{2 \mathrm{~m}}$. A night-time radiation fog extends to $800 \mathrm{~m}$ but lifts off the ground by late morning into a low cloud. An early morning boundary-layer cloud is also formed at around $4 \mathrm{~km}$, marking the top of the cooling moist residual layer. The simulated cloud, fog and dust profiles resemble those observed by the LIDAR on board Phoenix. The fog and cloud, albeit thin, are thick enough to induce weak effects on the modelled radiative fluxes.

These fairly good simulations by a mere 1D boundarylayer model are probably due to the fact that the Martian surface temperatures are so strongly forced by the radiative fluxes (Figure 2). These fluxes can and should be parametrized fairly accurately. It follows that $T_{\mathrm{g}}(t)$ can be well simulated if the thermodynamic properties of dust and the ground are known. Winds play only a secondary role (Figure 1), unlike on the Earth. Hence the 1D models with their simple wind assumptions can still be used profitably to simulate, interpret and understand the local boundary-layer thermodynamics of Mars (e.g. the present study; Taylor et al., 2007; Martinez et al., 2009; Möhlmann et al., 2009; Wolff et al., 2009), even if many large-scale, mesoscale and large-eddy simulation 3D models now exist for Mars. For realistic wind simulations, 3D dynamic models are obviously necessary, but even these models may benefit from the scheme development and sensitivity studies, which are easier to perform using the $1 \mathrm{D}$ approach.

\section{Acknowledgements}

Support by the Finnish Academy (contract 131723) is acknowledged. The two anonymous reviewers provided very valuable comments and remarks.

\section{References}

Atkinson BW. 1981. Meso-scale Atmospheric Circulations. Academic Press: New York.

Buck AL. 1981. New equations for computing vapour pressure and enhancement factor. J. Appl. Meteorol. 20: 1527-1532.
Ebert EE, Curry JA. 1992. A parameterization of ice cloud optical properties for climate models. J. Geophys. Res. 97(D4): 3831-3836.

Haltiner GJ, Williams RT. 1980. Numerical Prediction and Dynamic Meteorology. J. Wiley and Sons: New York.

Kauhanen J, Siili T, Järvenoja S, Savijärvi H. 2008. The Mars Limited Area Model and simulations of atmospheric circulations for the Phoenix landing area and season of operation. J. Geophys. Res. 113: E00A14, DOI: 10.1029/2007JE003011.

Leovy CB. 1982. Martian meteorological variability. Adv. Space Res. 2 : $19-44$.

Makkonen L, Laakso T. 2005. Humidity measurements in cold and humid environments. Boundary-Layer Meteorol. 116: 131-147.

Martinez G, Valero F, Vazquez L. 2009. Characterization of the Martian surface layer. J. Atmos. Sci. 66: 187-198.

Määttänen A, Vehkamäki H, Lauri A, Merikallio S, Kauhanen J, Savijärvi H, Kulmala M. 2005. Nucleation studies in the Martian atmosphere. J. Geophys. Res. 110: E02002, DOI: 10.10129/2004JE002308.

Määttänen A, Fouchet T, Forni O, Forget F. Savijärvi H, Gondet B, Melchiorri R, Langevin Y, Formisano V, Giuranna M, Bibring JP. 2009. A study of the properties of a local dust storm with Mars Express OMEGA and PFS data. Icarus 201: 504-516.

Möhlmann D, Niemand M, Formisano V, Savijärvi H, Wolkenberg P. 2009. Fog phenomena on Mars. Planet. Space Sci. 57: 1987-1992.

Read PL, Lewis SR. 2004. The Martian Climate Revisited: Atmosphere and Climate of a Desert Planet. Springer-Verlag, Praxis Publishing Ltd: Chichester, UK.

Savijärvi H. 1991. A model study of the PBL structure on Mars and the Earth. Contrib. Atmos. Phys. 64: 219-229.

Savijärvi H. 1992. On surface temperature and moisture prediction in atmospheric models. Contrib. Atmos. Phys. 65: 281-292.

Savijärvi H. 1995. Mars boundary layer modelling: Diurnal moisture cycle and soil properties at the Viking Lander 1 site. Icarus 117: $120-127$.

Savijärvi H. 1999. A model study of the atmospheric boundary layer in the Mars Pathfinder lander conditions. Q. J. R. Meteorol. Soc. 125: 483-493

Savijärvi H. 2009. Stable boundary layer: Parametrizations for local and larger scales. Q. J. R. Meteorol. Soc. 135: 914-921.

Savijärvi H, Kauhanen J. 2008. Surface and boundary-layer modelling for the Mars Exploration Rover sites. Q. J. R. Meteorol. Soc. 134: 635-641.

Savijärvi H, Siili T. 1993. The Martian slope winds and the nocturnal PBL jet. J. Atmos. Sci. 50: 77-88.

Savijärvi H, Määttänen A, Kauhanen J, Harri AM. 2004. Mars Pathfinder: new data and new model simulations. Q. J. R. Meteorol. Soc. 130: 669-683.

Savijärvi H, Crisp D, Harri AM. 2005. Effects of $\mathrm{CO}_{2}$ and dust on present-day solar radiation and climate in Mars. Q. J. R. Meteorol. Soc. 131: 2907-2922.

Smith MD, WolffMJ, Lemmon MT, Spanovich N, Banfield D, Budney CJ, Clancy RT, Ghosh A, Landis GA, Smith P, Whitney B, Christensen PR, Squyres S. 2004. First atmospheric results from the Mars Exploration Rovers mini-TES. Science 306: 1750-1753.

Smith PH, Tamppari LK, Arvidson RE, Bass D, Blaney D, Boynton WV, Carswell A, Catling DC, Clark BC, Duck T, DeJong E, Fisher D, Goetz W, Gunnlaugsson HP, Hecht MH, Hipkin V, Hoffman J, Hviid SF, Keller HU, Kounaves SP, Lange CF, Lemmon MT, Madsen MB, Markiewicz WJ, Marshall J, McKay CP, Mellon MT, Ming DW, Morris RV, Pike WT, Renno N, Staufer U, Stoker C, Taylor P, Whiteway JA, Zent AP. 2009. $\mathrm{H}_{2} \mathrm{O}$ at the Phoenix landing site. Science 325: 58-61.

Tamppari LK, Bass D, Cantor B, Daubar I, Dickinson C, Fisher D, Fujii K Gunnlauggson HP, Hudson TL, Kass D, Kleinböhl A, Komguem L, Lemmon MT, Mellon M, Moores J, Pankine A, Pathak J, Searls M, Seelos F, Smith MD, Smrekar S, Taylor P, Holstein-Rathlou C, Weng W, Whiteway J, Wolff M. 2010. Phoenix and MRO coordinated atmospheric measurements. J. Geophys. Res. 115: E00E17, DOI: 10.1029/2009JE003415.

Taylor PA, Li PY, Michelangeli DV, Pathak J, Weng W. 2007. Modelling dust distributions in the atmospheric boundary layer on Mars. Boundary-Layer Meteorol. 125: 305-328.

Vehkamäki H, Määttänen A, Lauri A, Napari I, Kulmala M. 2007. Technical note: The heterogeneous Zeldovich factor. Atmos. Chem. Phys. 7: 309-313.

Whiteway JA, Komguem L, Dickinson C, Cook C, Illnicki M, Seabrook J, Popovici V, Duck TJ, Davy R, Taylor PA, Pathak J, Fisher D, Carswell AI, Daly M, Hipkin V, Zent AP, Hecht MH, Wood SE, Tamppari LK, Renno N, Moores JE, Lemmon MT, Daerden F, Smith PH. 2009. Mars water-ice clouds and precipitation. Science 325: $68-70$. 
Wolff MJ, Smith MD, Clancy RT, Arvidson R, Kahre M, Seelos F IV, Murchie S, Savijärvi H. 2009. Wavelength dependence of dust aerosol single scattering albedo as observed by the Compact Reconnaissance Imaging Spectrometer. J. Geophys. Res. 114: E00D04, DOI: 10.129/2009JE003350.
Zent AP, Hecht MH, Cobos DR, Wood SE, Hudson TL, Milkovich SM, DeFlores LP, Mellon MT. 2010. Initial results from the Thermal and Electrical Conductivity Probe (TECP) on Phoenix. J. Geophys. Res. 115: E00E14, DOI: 10.1029/2009JE003420. 